OPEN ACCESS

Edited by:

Salem Chouaib,

Institut Gustave Roussy, France

Reviewed by:

O. Graciela Scharovsky,

National University of Rosario,

Argentina

Ronca Roberto,

University of Brescia, Italy

*Correspondence: Antonio Giovanni Solimando

antonio.solimando@uniba.it Markus Krebs krebs_m@ukw.de

Specialty section:

This article was submitted to

Cancer Immunity

and Immunotherapy,

a section of the journal

Frontiers in Immunology

Received: 23 December 2021 Accepted: 21 January 2022

Published: 10 February 2022

Citation:

Solimando AG, Kalogirou C and Krebs M (2022) Angiogenesis as

Therapeutic Target in Metastatic

Prostate Cancer - Narrowing the Gap

Between Bench and Bedside.

Front. Immunol. 13:842038. doi: 10.3389/fimmu.2022.842038

\section{Angiogenesis as Therapeutic Target in Metastatic Prostate Cancer - Narrowing the Gap Between Bench and Bedside}

\author{
Antonio Giovanni Solimando ${ }^{1,2 *}$, Charis Kalogirou ${ }^{3}$ and Markus Krebs ${ }^{3,4 *}$ \\ ${ }^{1}$ Department of Biomedical Sciences and Human Oncology, Section of Internal Medicine "G. Baccelli", University of Bari \\ Medical School, Bari, Italy, ${ }^{2}$ Medical Oncology Unit, Istituto di Ricovero e Cura a Carattere Scientifico (IRCCS) Istituto Tumori \\ "Giovanni Paolo II", Bari, Italy, ${ }^{3}$ Department of Urology and Pediatric Urology, University Hospital Würzburg, Würzburg, \\ Germany, ${ }^{4}$ Comprehensive Cancer Center Mainfranken, University Hospital Würzburg, Würzburg, Germany
}

Angiogenesis in metastatic castration-resistant prostate cancer (mCRPC) has been extensively investigated as a promising druggable biological process. Nonetheless, targeting angiogenesis has failed to impact overall survival (OS) in patients with mCRPC despite promising preclinical and early clinical data. This discrepancy prompted a literature review highlighting the tumor heterogeneity and biological context of Prostate Cancer (PCa). Narrowing the gap between the bench and bedside appears critical for developing novel therapeutic strategies. Searching clinicaltrials.gov for studies examining angiogenesis inhibition in patients with PCa resulted in $n=20$ trials with specific angiogenesis inhibitors currently recruiting (as of September 2021). Moreover, several other compounds with known anti-angiogenic properties - such as Metformin or Curcumin - are currently investigated. In general, angiogenesis-targeting strategies in PCa include biomarker-guided treatment stratification - as well as combinatorial approaches. Beyond established angiogenesis inhibitors, PCa therapies aiming at PSMA (Prostate Specific Membrane Antigen) hold the promise to have a substantial anti-angiogenic effect - due to PSMA's abundant expression in tumor vasculature.

Keywords: Prostate adenocarcinoma, PCa, angiogenesis inhibitors, TKI, immunotherapy, tumor microenvironment, clinical trials, PSMA

\section{INTRODUCTION}

The biological context of angiogenesis and prostate cancer (PCa) inspired a plethora of research, specifically in metastatic PCa and more specifically in castration-resistant disease (CRPC), the clinical stage in which the majority of clinical trials on angiogenesis inhibition was performed (1). Metastatic $\mathrm{PCa}$ is an androgen-driven and -dependent cancer (2), with androgen deprivation therapy (ADT) being the primary treatment. Despite high response rates - practically $90 \%$ of patients initially respond to hormone therapy - the vast majority will end up relapsing (3) in a predictable and irreversible manner. There has been a fair amount of research to try to analyze the mechanisms of progression to $\mathrm{CRPC}$, which is the lethal phenotype of metastatic $\mathrm{PCa}$ - and current evidence suggest a function of 
clonal selection and adaptation by androgen receptor (AR)dependent and independent mechanisms (4).

Indeed, ADT together with next generation hormonal agents such as Abiraterone (5) and Enzalutamide (6) still represent the foundation of systemic PCa treatment. Beyond hormone therapy, approved chemotherapy regimens mainly consist of Docetaxel and Cabazitaxel as microtubule inhibitors (7-9). Regarding bone as a favorite localization of PCa metastasis (10-12), therapeutic (combination) approaches include Radium-223 (13). In recent years, PCa treatment has rapidly developed towards precision oncology by addressing two novel target pathways: DNA repair and Prostate-specific membrane antigen (PSMA)-related signaling. Regarding DNA repair, cancers with mutations in BRCA1/2 (Breast Cancer Associated Genes 1 and 2) can be treated with PARP (Poly-ADP-Ribose-Polymerase) inhibitors originally established in Ovarian Cancer $(14,15)$. For PSMA, strategies include radioligand therapy as a theragnostic approach performed by nuclear medicine specialists (16).

Beyond these established and approved cancer therapies, this review aims to address an obvious treatment gap - given the crucial role of angiogenesis for PCa development and progression. Despite this fundamental promise reflected by in vitro and preclinical evidence, phase III trials with angiogenesis inhibitors failed to meet clinical endpoints.

\section{PROSTATE CANCER AND VEGF- MEDIATED ANGIOGENESIS - PROMISES AND CHALLENGES}

About 50 years ago, Folkman and colleagues highlighted the importance of angiogenesis and neovascularization for tumor growth - reasoning that targeting tumor blood vessels might prove beneficial for patients with cancer (17). Meanwhile, stateof-the-art techniques highlighted the crucial but not completely understood link between angiogenesis (endothelial cells) and tumor immunity (18). For PCa, histopathology pinpoints high micro-vessel density and increased VEGF (Vascular Endothelial Growth Factor) expression compared to non-neoplastic conditions. Moreover, VEGF levels are associated with higher tumor stages as well as advanced grading and plasma VEGF is increased in metastatic PCa versus localized disease (19-21). Higher VEGF expression evaluated by immunohistochemistry has also been associated with reduced disease-specific survival in patients with PCa (22). In addition, levels of urinary VEGF were associated with worse survival (23) and elevated plasma VEGF/ sVCAM-1, a vascular cell adhesion molecule, correlated with worse outcome (24).

In principle, many drugs and angiogenic target structures known from other solid and hematological malignancies are available for PCa (25-30). As a consequence, clinical trials combined antiangiogenic agents with Taxanes in mCRPC (31); however, not a single drug combined with Docetaxel showed a statistically significant success in terms of outcome (32). Therefore, clinicians started trials in less symptomatic patients, investigating compounds as single agents. Unfortunately, all of these phase III trials with thousands of patients were collectively negative for OS - despite promising biological preclinical as well as promising phase II trials. Despite efforts studying more than 1,000 patients, the combination of Bevacizumab or Aflibercept with chemotherapy showed no improvement compared to chemotherapy alone $(33,34)$. Sunitinib as a single agent compared to prednisone showed no improvement, either (35).

Making it even worse, Lenalidomide treatment resulted in a sobering scenario (36): While effective in several hematologic conditions (37-40), combination treatment of patients with PCa (Lenalidomide + Docetaxel + Prednisone) led to a significantly worse OS compared to treatment with Docetaxel and Prednisone (36). Another surprising and quite sobering example is Cabozantinib, an oral inhibitor of Tyrosine Kinases including MET and VEGFR2, two major drivers of malignant progression in several neoplasia (41-47), which did not guarantee an OS advantage in patients with PCa (48). Indeed, Cabozantinib showed anti-angiogenic and antitumor effects in a wide range of preclinical tumor models (49-51), also blocking progression of PCa xenografts in soft tissue and bone (52-54). Additionally, Cabozantinib affected key actors of the bone niche with reduction in osteoclasts and biphasic effects osteoblasts, while altering bone remodeling with increased volume in mice (55). MET and VEGFR2 cooperate to promote tumor survival, thereby boosting angiogenesis via improved tumor blood flow and improved oxygenation. Moreover, MET promotes migration and invasion, also facilitating the escape from hypoxic areas. Consequently, bone metastases are associated with high levels of MET expression. In specific, MET expression increased with androgen deprivation in preclinical models and with progression and metastasis in bone and lymph nodes (56). Promising early phase II trial results from bone scans upon combined Docetaxel and Cabozantinib treatment showed activity in 300 patients $(48,57)$. Soft tissue effects were also present, with objective response and significant progression-free survival (PFS) benefit (48). Improvement in pain and reduction of narcotics corroborated these initial results (58). These data were paralleled by a reduction of circulating tumor cells (57), while keeping activity in subjects heavily pretreated with Docetaxel, Abiraterone and/or Enzalutamide $(48,57)$. The lowest effective dose of these studies was $40 \mathrm{mg} /$ day (59). Nevertheless, within phase III trial, Cabozantinib did not perform better than Prednisone (60). The dose and the stage of disease could have been the cause for this failure.

\section{CURRENT CLINICAL TRIALS ON ANTI- ANGIOGENESIS IN PROSTATE CANCER}

To determine the status quo of clinical trials investigating antiangiogenesis in $\mathrm{PCa}$, we performed a database research on clinicaltrials.gov. As of September 2021, a total sum of 866 actively recruiting interventional trials were registered for patients suffering from PCa. As outlined in Table 1, only a minority of clinical trials investigated the effects of angiogenesis inhibitors/Tyrosine kinase inhibitors. Specifically, we identified 20 clinical trials addressing angiogenesis inhibition. While some 
TABLE 1 | Recruiting interventional trials examining anti-angiogenesis in prostate cancer (PCa) registered within clinicaltrials.gov database (December 2021).

\begin{tabular}{|c|c|c|c|c|}
\hline $\begin{array}{l}\text { Trial } \\
\text { Identifier }\end{array}$ & Stage/Entity & Title/characteristics & Treatment & Comment \\
\hline NCT01567800 & $\mathrm{PCa}$ & Prostate Hypoxia FAZA & 18F-FAZA & Hypoxia-specific PET tracer \\
\hline NCT02465060 & Advanced Cancer & $\begin{array}{l}\text { MATCH screening trial; } \\
\text { Phase II }\end{array}$ & $(\ldots)$, Sunitinib, $(\ldots)$ & $\begin{array}{l}\text { Biomarker-driven Basket trial for } \\
\text { various compounds }\end{array}$ \\
\hline NCT02484404 & Advanced solid tumors & Phase $1 / \|$ & $\begin{array}{l}\text { Combinations of Cediranib, Durvalumab and } \\
\text { Olaparib }\end{array}$ & Cediranib: pan-VEGFR inhibitor \\
\hline NCT02643667 & Localized PCa & Phase I/II & Ibrutinib before Radical Prostatectomy & $\begin{array}{l}\text { Ibrutinib: BTK inhibitor; Neoadjuvant } \\
\text { setting }\end{array}$ \\
\hline NCT03170960 & Advanced solid tumors & Phase $1 / \|$ & Cabozantinib \pm Atezolizumab & \\
\hline NCT03385655 & $\mathrm{PCa}$ & Phase II & (...), Savolitinib, (...) & $\begin{array}{l}\text { Biomarker-driven therapy } \\
\text { stratification }\end{array}$ \\
\hline NCT03556228 & PCa and other malignancies & Phase I & VMD-928 & VMD-928: TrkA inhibitor \\
\hline NCT03845166 & Advanced solid tumors & Phase I & $\begin{array}{l}\text { XL092 AND Atezolizumab OR XL092 AND } \\
\text { Avelumab }\end{array}$ & $\begin{array}{l}\text { XL092: Tyrosine Kinase inhibitor } \\
\text { (incl. VEGFR2) }\end{array}$ \\
\hline NCT03866382 & Rare genitourinary tumors & Phase II & $\begin{array}{l}\text { Cabozantinib AND Nivolumab AND } \\
\text { Ipilimumab }\end{array}$ & $\begin{array}{l}\text { Metastatic Prostate Small Cell } \\
\text { Neuroendocrine CA }\end{array}$ \\
\hline NCT03878524 & Advanced Cancer & SMMART; Phase I & $\begin{array}{l}\text { (...), Bevacizumab, Cabozantinib, Sorafenib, } \\
\text { Sunitinib, (...) }\end{array}$ & $\begin{array}{l}\text { Biomarker-driven Basket trial for } \\
\text { various compounds }\end{array}$ \\
\hline NCT03964337 & PCa before surgery & SPARC; Phase ॥ & Neoadjuvant Cabozantinib & \\
\hline NCT04159896 & mCRPC & Phase II & ESK981 AND Nivolumab & ESK981: Pan-VEGFR/TIE2 inhibitor \\
\hline NCT04446117 & mCRPC & CONTACT-02; Phase III & Cabozantinib AND Atezolizumab & \\
\hline NCT04477512 & mCSPC & CABIOS; Phase I & $\begin{array}{l}\text { Cabozantinib AND Abiraterone/Prednisone } \\
\text { AND Nivolumab }\end{array}$ & \\
\hline NCT04514484 & Advanced Cancer AND HIV infection & Phase I & Cabozantinib AND Nivolumab & \\
\hline NCT04521686 & $\begin{array}{l}\text { Advanced solid tumors with IDH1 } \\
\text { mutations }\end{array}$ & Phase I & LY3410738 & LY3410738: IDH1 inhibitor \\
\hline NCT04631744 & $\mathrm{mCRPC}$ & Phase II & Cabozantinib & \\
\hline NCT04635059 & PCa: biochemical recurrence & BLAST; Phase ॥ & Pacritinib & Pacritinib: JAK/FLT3 inhibitor \\
\hline NCT04742959 & Advanced solid tumors & Phase $1 / \|$ & TT-00420 \pm Nab-Paclitaxel & $\begin{array}{l}\text { TT-00420: Tyrosine Kinase inhibitor } \\
\text { (incl. VEGFRs) }\end{array}$ \\
\hline NCT04848337 & $\begin{array}{l}\text { Advanced/metastatic neuroendocrine } \\
\text { PCa }\end{array}$ & PLANE-PC; Phase ॥ & Lenvatinib AND Pembrolizumab & Lenvatinib: VEGFR inhibitor \\
\hline \multicolumn{5}{|c|}{ Further compounds with known anti-angiogenic properties } \\
\hline NCT02935205 & CRPC & Phase I/II & Indomethacin AND Enzalutamide & \\
\hline NCT00268476 & mCSPC & STAMPEDE; Phase II/III & $(\ldots)$, Metformin, $(\ldots)$ & \\
\hline NCT01864096 & low-risk PCa under Active Surveillance & MAST; Phase III & Metformin & \\
\hline NCT02064673 & PCa after Radical Prostatectomy & Phase III & Curcumin & \\
\hline NCT02176161 & $\begin{array}{l}\text { PCa after therapy and a high-risk } \\
\text { setting }\end{array}$ & Phase II & Metformin & \\
\hline NCT02804815 & $\begin{array}{l}\text { PCa and other malignancies after } \\
\text { curative therapy }\end{array}$ & Phase III & Aspirin & \\
\hline NCT03031821 & PCa with indication for ADT & PRIME; Phase III & Metformin AND ADT & \\
\hline NCT03535675 & $\begin{array}{l}\text { PCa: PSA recurrence after definitive } \\
\text { treatment }\end{array}$ & Phase III & Muscadine Grape extract & $\begin{array}{l}\text { Patient pre-selection according to } \\
\text { genotype }\end{array}$ \\
\hline NCT03769766 & low-risk PC under Active Surveillance & Phase III & Curcumin & \\
\hline NCT03819101 & CRPC & PEACE-4; Phase III & Acetylsalicylic acid \pm Atorvastatin & \\
\hline NCT03899987 & PCa before Radical Prostatectomy & Phase II & $\begin{array}{l}\text { Aspirin AND Rintatolimod } \pm \text { interferon-alpha } \\
2 \mathrm{~b}\end{array}$ & \\
\hline NCT04300855 & PCa under Active Surveillance & Phase ॥ & Green Tea Catechins (Sunphenon) & \\
\hline NCT04519879 & PCa: recurrent/therapy-naive & Phase III & White Button Mushroom extract & \\
\hline NCT04536805 & $\begin{array}{l}\text { PCa: relapse in previously irradiated } \\
\text { Prostate bed }\end{array}$ & $\begin{array}{l}\text { REPAIRGETUGP16; } \\
\text { Phase I/II }\end{array}$ & Metformin AND Radiation & \\
\hline NCT04597359 & PCa under Active Surveillance & Phase ॥ & Green Tea Catechins & \\
\hline
\end{tabular}

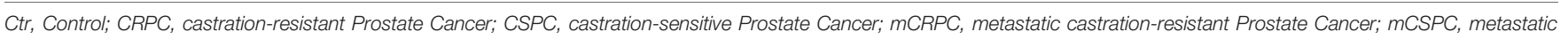
castration-sensitive Prostate Cancer; ADT, Androgen deprivation therapy.

studies aim to identify predictive biomarkers for future clinical stratification in entity-independent trials (NCT02465060, NCT03878524), others combine angiogenesis inhibition with immune checkpoint blockade - e. g. CONTACT-02 trial investigating Cabozantinib in combination with Atezolizumab in patients with mCRPC (NCT04446117). Of note, other studies include patients in different stages, such as metastatic castration sensitive disease (CABIOS phase I trial, NCT04477512) and even localized disease in a neoadjuvant setting before Radical Prostatectomy (SPARC phase II trial, NCT03964337).

Beyond this relatively small number of trials directly aiming at tumor vessels, we found several studies investigating 
compounds known to have additional anti-angiogenic effects (bottom part of Table 1). Curcumin, Green Tea Catechins and Metformin were among the substances identified. For Metformin, a tumor suppressive role was shown in several cancer entities (61). Moreover, adjuvant Metformin intake was associated with improved outcome in Clear Cell Renal Cell Carcinoma patients treated with Tyrosine Kinase inhibitors in two independent cohorts $(62,63)$. One reason for this protective effect could be the role of Metformin as a mitochondrial inhibitor. Interestingly, recent evidence implies a prominent role for mitochondrial signaling not only in Clear Cell Renal Cell Carcinoma (64), but also in high-grade PCa (65). Potentially, angiogenesis inhibition could be more effective in patients suffering from PC when combined with adjuvants such as Metformin.

\section{DISCUSSION}

From a histopathological and preclinical perspective, there is convincing evidence for a significant role of angiogenesis in $\mathrm{PCa}$ development and progression. For example, VEGFR2 was shown to mark PCa cases with a high risk of progression $(30,66)$. In addition, angiogenesis-related microRNAs such as let-7, miR-195 and miR205 (67) are also deregulated and play prominent roles in PCa (6870). However, no angiogenesis-specific inhibitor has met its clinical endpoint in phase III trials (see Figure 1A). Consequently, angiogenesis inhibitors currently do not play a role in $\mathrm{PCa}$ treatment guidelines. As shown by our database search on clinicaltrials.gov, several clinical trials are currently recruiting patients with PCa to address the discrepancy between promising preclinical findings and sobering clinical trial results.

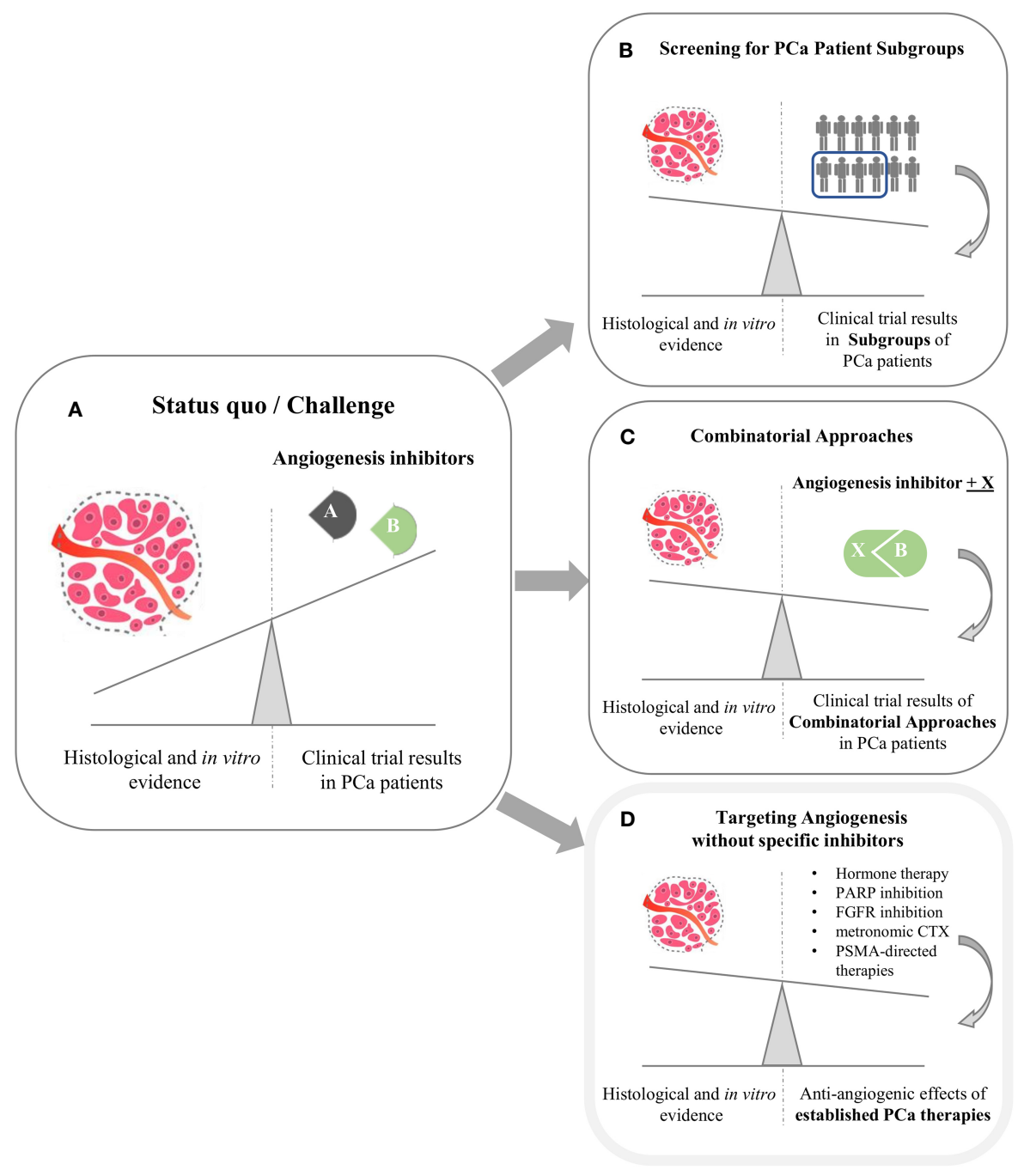

FIGURE 1 | The clinical challenge of angiogenesis inhibition in Prostate Cancer (PCa). (A) Despite promising preclinical evidence from histopathological and in vitro analyses, phase III clinical trials with angiogenesis inhibitors failed to meet clinical endpoints. (B, C) Main strategies aiming to leverage the impact of angiogenesis inhibition are biomarker-aided identification of PC patient subgroups most susceptible towards anti-angiogenesis (B) and combinatorial approaches (C). Moreover, several established PCa therapies partly exhibit anti-angiogenic effects as mode of action (D). 


\section{Current Therapeutic Strategies to Narrow the Gap Between Bench and Bedside}

As illustrated in Figure 1, two main strategies aim to establish therapeutic anti-angiogenesis in patients with $\mathrm{PCa}$. Within the first strategic approach, clinicians are searching for $\mathrm{PCa}$ subgroups most susceptible towards angiogenesis inhibition (Figure 1B). It is tempting to assume that targeting tumor neovascularization could be more efficient when used early in the course of disease (71) in order to prevent metastases $(44,72)$. In line with this assumption, clinicians examine effects in $\mathrm{PCa}$ subgroups other than mCRPC. Specifically, SPARC investigates Cabozantinib in a neoadjuvant setting. PCa patients suffering from biochemical recurrence are currently recruited for the BLAST trial, which investigates the JAK/FLT3 inhibitor Pacritinib. Moreover, the CABIOS trial recruits CSPC patients receiving Cabozantinib, Abiraterone and Nivolumab (thereby also representing the second strategic approach of combinatorial therapies). Up to now, neither predictive nor response biomarkers have been established to stratify PCa patients regarding anti-angiogenic therapy $(18,26)$. Of note, most biomarker-driven trials trying to meet the needs are not PCaspecific. Recruiting patients suffering from advanced cancer, the MATCH screening trial constitutes a biomarker-driven basket study for various compounds including Sunitinib. In a similar setting, SMMART investigates compounds such as Bevacizumab, Cabozantinib, Sorafenib and Sunitinib.

As a second strategic approach to narrow the gap between bench and bedside (Figure 1C), clinicians and researchers combine angiogenesis inhibitors with other established cancer compounds. Most of the respective trials identified by our search teamed angiogenesis inhibitors with immune checkpoint inhibitors (ICI) - e. g. Cabozantinib and Atezolizumab (CONTACT-02 trial). However, the primary rationale of these approaches is not to establish anti-angiogenesis as a treatment option for $\mathrm{PCa}$, but to break therapy resistance towards ICI (73-75).

\section{BRCA in Metastatic Prostate Cancer - Recommendations and Perspectives}

As a second bullet point to envision next steps narrowing the gap between the bench and bedside, it is important to highlight that genetic alterations of BRCA2 and BRCA1 occur in metastatic PCa with a frequency of $13 \%$ and $5.3 \%$ for the somatic component, and $0.3 \%$ and $0.9 \%$ for the germline component, respectively $(76,77)$. Germline mutations in BRCA2 are associated with pathways also related to VEGF signaling (78). Thus, phase II and III studies investigating effect on PFS and ORR in MCRPC hold promise to further elucidate the complex relationship of disease biology, since genomic alterations and several genes are screened (Table 2). TRITON2 and GALAHAD studies showed objectives and PSA responses in patients with BRCA1/2 alterations employing Rucaparib and Niraparib, respectively $(79,80)$. Nonetheless, the Profound trial testing Olaparib, confirmed that BRCA2 is the most frequently altered gene and with BRCA1 and ATM genes allowed to reach a radiographic PFS improvement of Olaparib treated over control (HR.34 P<.0001, CI.25-.47). Those results are remarkable since checkpoint inhibitors may have limited efficacy in PCa as single agents; thus, combination approaches are being examined to potentially improve their efficacy in this as in other urological diseases $(30,44)$. The hypothetical synergism between PARP inhibitors and ICI is centered on evidence that DNA damage resulting from PARP inhibition triggers the cGAS-STING pathway (81), which consequently boosts the interferon signaling, leading to enhanced immunogenicity (82). There is also rationale for an additive effect in cancers with high microsatellite instability (MSI) and BRCA mutations (83). Moreover, cancers with CDK12 mutations are often sensitive to PARP inhibitors - and preclinical and biological data from patients with PCa showed that CDK12 inactivation is related to increased burden of neoantigens, which can in turn enhance the immunogenicity (84). ICI hold anti-mCRPC activity potential in high degree of MSI. Indeed, the KEYNOTE-365 trial comparing Pembrolizumab plus Olaparib in biomarker-unstratified mCRPC subjects after prior taxane-based regimen uncovered that $36.6 \%$ of

TABLE 2 | Trials screening genes involved in prostate cancer (PCa) registered within clinicaltrials.gov database (December 2021). See text for details.

\begin{tabular}{|c|c|c|c|}
\hline & PROFOUND & TRITON 2 & GALAHAD \\
\hline Drug & Olaparib 300 mg bid & Rucaparib 600 mg bid & Niraparib 300 mg qd \\
\hline $\begin{array}{l}\text { Study } \\
\text { design }\end{array}$ & Phase III & Phase II & Phase ॥ \\
\hline Population & mCRPC progression to ARSI & mCRPC progression to ARSI and taxane & $\begin{array}{l}\text { mCRPC progression to } \\
\mathrm{ARSI} \text { and taxane }\end{array}$ \\
\hline $\begin{array}{l}\text { Primary } \\
\text { objective }\end{array}$ & rPFS in pts with alterations in ATM, BRCA1, BRCA2 & $\begin{array}{l}\text { ORR and PSA response ( } \geq 50 \% \text { decline) in pts with DDR } \\
\text { alterations }\end{array}$ & $\begin{array}{l}\text { ORR in patients with bi- } \\
\text { allelic BRCA1/2 alterations }\end{array}$ \\
\hline $\begin{array}{l}\text { Specimen } \\
\text { tested }\end{array}$ & Tumor tissue central & Plasma or tumor tissue central/local & Plasma central \\
\hline Test used & FoundationOne ${ }^{\circledR}$ & $\begin{array}{l}\text { FoundationOne }{ }^{\circledR} \\
\text { FoundationACT }{ }^{\circledR} \\
\text { Local }\end{array}$ & Resolution-HRD ${ }^{\circledR}$ \\
\hline $\begin{array}{l}\text { Genes } \\
\text { screened }\end{array}$ & $\begin{array}{l}\text { ATM, BARD1, BRCA1, BRCA2, BRIP1, CDK12, CHEK1, } \\
\text { CHEK2, FANCL, PALB2, PPP2RA, RAD51B, RAD51C, } \\
\text { RAD51D, RAD54L }\end{array}$ & $\begin{array}{l}\text { ATM, BARD1, BRCA1, BRCA2, BRIP1, CDK12, CHEK2, } \\
\text { FANCA, NBN, PALB2, RAD51, RAD51B, RAD51C, } \\
\text { RAD51D, RAD54L }\end{array}$ & $\begin{array}{l}\text { ATM, BRCA1, BRCA2, } \\
\text { BRIP1, CHEK2, FANCA, } \\
\text { HDAC2, PALB2 }\end{array}$ \\
\hline $\begin{array}{l}\text { Genomic } \\
\text { alteration } \\
\text { required }\end{array}$ & Mono- and Bi- allelic alterations in DDR genes & Mono- and Bi- allelic alterations in DDR genes & $\begin{array}{l}\text { Bi- allelic alterations in } \\
\text { DDR genes }\end{array}$ \\
\hline
\end{tabular}


individuals obtained a PSA response (85). The KEYLYNK-010 phase III study has been designed to deeper elucidate the combination of Pembrolizumab plus Olaparib in patients with mCRPC in a biomarker-unselected population after progression on androgendeprivation therapy and androgen receptor signaling inhibitor (86). In line with this, Nivolumab plus Rucaparib in the phase II CheckMate 9KD trial focusing on mCRPC revealed that best response rates were among BRCA2 mutated cases and that the combination was not efficient in individuals without homologous recombination mutations (87). Statistically powered studies aiming to corroborate these hypothesis-generating results are needed. Nonetheless, based on the available data, the FDA approved both Niraparib and Rucaparib as well as Olaparib in May 2020 (88). Nonetheless, EMA approved Olaparib for the treatment of patients with mCRPC and BRCA1/2 mutations, either germline or somatic after progression following a prior line including a hormonal agent, based on the results published by Hussain M. et al. (89). Collectively, the BRCA mutational status assessment in mCRPC is not merely a predictor of response to PARP inhibition, but is rather a biomarker of aggressiveness and therefore can sketch a disease phenotype for whom additional biomarker might be added (90). Indeed, BRCA status might also predict a decreased taxane sensitivity compared to Abiraterone and Enzalutamide, nonetheless confirmatory trials are also needed.

\section{Targeting Angiogenesis Without Specific Inhibitors - Established and Evolving Therapies}

While our database search on clinicaltrials.gov revealed a limited number of studies with specific inhibitors of angiogenesis, a plethora of trials investigated compounds such as antiandrogens, PARP inhibitors and PSMA-directed agents. At first sight, these approaches might not appear tightly related to tumor angiogenesis. Yet, recent findings imply that all these strategies obtain a significant anti-angiogenic component. Regarding AR-related signaling, a growing amount of literature investigates the complex crosstalk with VEGF-mediated pathways in cancer (91). As mentioned, for PARP inhibitors such as Olaparib, an anti-angiogenic effect besides an anti-mCRPC is widely accepted $(14,92,93)$. Moreover, FGF (Fibroblast Growth Factor) and its receptors (FGFRs) play prominent pro-angiogenic roles in several malignancies, including PCa $(94,95)$. Consequently, the FGFR inhibitor Erdafitinib is currently investigated in patients with CRPC as a single drug (NCT04754425) and combined with Abiraterone or Enzalutamide in patients with CRPC (NCT03999515).

Metronomic (low-dose) chemotherapy is another welldescribed therapeutic strategy to target tumor-associated neovasculature in various cancer entities. Frequent and regular administration of chemotherapeutic agents at doses constituting a fraction of the MTD (maximum tolerated dose) was shown to have substantial therapeutic effects - especially on tumor endothelium. Moreover, these regimens frequently exhibited favorable toxicity profiles $(96,97)$. For PCa, clinical evidence highlights the potential of metronomic therapies especially in mCRPC: studies investigated metronomic Cyclophosphamide in combination with Docetaxel (98) or in heavily pretreated patients after Docetaxel or Abiraterone/Enzalutamide (99-102) - showing effectiveness and good tolerability. In addition, researchers examined the efficacy of metronomic application of Vinorelbine (103) and metronomic Cyclophosphamide, Celecoxib and Dexamethasone in patients suffering from mCRPC (104). Interestingly, metronomic Cyclophosphamide application also induced an immune reaction (in terms of $\mathrm{T}$ cell reactivation) in patients with biochemical recurrence (105). Although the mode of action of metronomic therapies is not completely understood, a recent study identified key genes which were associated with (metronomic) Topotecan dosing in PCa cell lines (106).

Regarding PSMA, receptor expression not only exists on the surface of PCa cells. Instead, tumor-associated endothelium frequently displays robust levels of PSMA in various cancer entities (107-109). Future research must show the impact of targeting PSMA in terms of anti-angiogenic activity - for PCa but also for other entities with PSMA-positive tumor endothelium. Given the rationale of adding angiogenesis inhibitors to ICI in order to break resistance towards immune-based approaches (73-75), it also appears tempting to assume that targeting PSMA could have an impact on the immunogenicity of PCa.

In a nutshell: While specific angiogenesis inhibitors currently do not have an established role in PCa, targeting tumor angiogenesis and tumor-associated blood vessels probably is part of established PCa therapies - especially regarding PSMA-directed approaches.

\section{CONCLUSION}

Targeting angiogenesis with specific inhibitors unfortunately has failed to impact OS in patients with mCRPC despite promising early data - and despite convincing clinical activity in several other malignancies. This discrepancy highlights the importance of the microenvironment niche, as PCa is characterized by substantial inter- and intra-patient heterogeneity and adaptive biology. Therapeutic strategies to overcome this challenge include biomarker-guided screening for patient subgroups most likely to benefit from anti-angiogenesis. Moreover, several trials investigate combinatorial approaches. Beyond specific angiogenesis inhibitors, approved compounds such as antiandrogens, PARP inhibitors and PSMA-targeting approaches probably also have a substantial antiangiogenic impact in PCa biology.

\section{AUTHOR CONTRIBUTIONS}

Conceptualization: AS and MK. Methodology: AS and MK. Writing - draft preparation: AS, CK, and MK. Writing review and editing: AS, CK, and MK. All authors contributed to the article and approved the submitted version.

\section{FUNDING}

This project was supported in part by the Apulian Regional Project Medicina di Precisione to A.G.S. Moreover, M.K. was funded by a personal grant from Else-Kröner-Foundation (Else Kröner Integrative Clinician Scientist College for Translational Immunology, University Hospital Würzburg, Germany). This publication was supported by the Open Access Publication Fund of the University of Würzburg. 


\section{REFERENCES}

1. Nicholson B, Theodorescu D. Angiogenesis and Prostate Cancer Tumor Growth. J Cell Biochem (2004) 91:125-50. doi: 10.1002/jcb.10772

2. Noble RL. Hormonal Control of Growth and Progression in Tumors of Nb Rats and a Theory of Action. Cancer Res (1977) 37:82-94.

3. Isaacs JT, Coffey DS. Adaptation Versus Selection as the Mechanism Responsible for the Relapse of Prostatic Cancer to Androgen Ablation Therapy as Studied in the Dunning R-3327-H Adenocarcinoma. Cancer Res (1981) 41:5070-5.

4. Debes JD, Tindall DJ. Mechanisms of Androgen-Refractory Prostate Cancer. N Engl J Med (2004) 351:1488-90. doi: 10.1056/NEJMp048178

5. Fizazi K, Tran N, Fein L, Matsubara N, Rodriguez-Antolin A, Alekseev BY, et al. Abiraterone Plus Prednisone in Metastatic, Castration-Sensitive Prostate Cancer. N Engl J Med (2017) 377:352-60. doi: 10.1056/NEJMoa1704174

6. Scher HI, Fizazi K, Saad F, Taplin M-E, Sternberg CN, Miller K, et al. Increased Survival With Enzalutamide in Prostate Cancer After Chemotherapy. N Engl J Med (2012) 367:1187-97. doi: 10.1056/NEJMoa1207506

7. Tannock IF, de Wit R, Berry WR, Horti J, Pluzanska A, Chi KN, et al. Docetaxel Plus Prednisone or Mitoxantrone Plus Prednisone for Advanced Prostate Cancer. N Engl J Med (2004) 351:1502-12. doi: 10.1056/NEJMoa040720

8. Tucci M, Bertaglia V, Vignani F, Buttigliero C, Fiori C, Porpiglia F, et al. Addition of Docetaxel to Androgen Deprivation Therapy for Patients With Hormone-Sensitive Metastatic Prostate Cancer: A Systematic Review and MetaAnalysis. Eur Urol (2016) 69:563-73. doi: 10.1016/j.eururo.2015.09.013

9. de Wit R, de Bono J, Sternberg CN, Fizazi K, Tombal B, Wülfing C, et al. Cabazitaxel Versus Abiraterone or Enzalutamide in Metastatic Prostate Cancer. N Engl J Med (2019) 381:2506-18. doi: 10.1056/NEJMoa1911206

10. Antonio G, Oronzo B, Vito L, Angela C, Antonel-la A, Roberto C, et al. Immune System and Bone Microenvironment: Rationale for Targeted Cancer Therapies. Oncotarget (2020) 11:480-7. doi: 10.18632/oncotarget.27439

11. Argentiero A, Solimando AG, Brunetti O, Calabrese A, Pantano F, Iuliani M, et al. Skeletal Metastases of Unknown Primary: Biological Landscape and Clinical Overview. Cancers (2019) 11:1270. doi: 10.3390/cancers11091270

12. Body J-J, Casimiro S, Costa L. Targeting Bone Metastases in Prostate Cancer: Improving Clinical Outcome. Nat Rev Urol (2015) 12:340-56. doi: 10.1038/ nrurol.2015.90

13. Cursano MC, Iuliani M, Casadei C, Stellato M, Tonini G, Paganelli G, et al. Combination Radium-223 Therapies in Patients With Bone Metastases From Castration-Resistant Prostate Cancer: A Review. Crit Rev Oncol Hematol (2020) 146:102864. doi: 10.1016/j.critrevonc.2020.102864

14. Konstantinopoulos PA, Matulonis UA. PARP Inhibitors in Ovarian Cancer: A Trailblazing and Transformative Journey. Clin Cancer Res (2018) 24:4062-5. doi: 10.1158/1078-0432.CCR-18-1314

15. Ratta R, Guida A, Scotté F, Neuzillet Y, Teillet AB, Lebret T, et al. PARP Inhibitors as a New Therapeutic Option in Metastatic Prostate Cancer: A Systematic Review. Prostate Cancer Prostatic Dis (2020) 23:549-60. doi: 10.1038/s41391-020-0233-3

16. Sartor O, de Bono J, Chi KN, Fizazi K, Herrmann K, Rahbar K, et al. Lutetium-177-PSMA-617 for Metastatic Castration-Resistant Prostate Cancer. N Engl J Med (2021) 385:1091-103. doi: 10.1056/NEJMoa2107322

17. Sherwood LM, Parris EE, Folkman J. Tumor Angiogenesis: Therapeutic Implications. N Engl J Med (1971) 285:1182-6. doi: 10.1056/NEJM197111182852108

18. Solimando AG, Summa SD, Vacca A, Ribatti D. Cancer-Associated Angiogenesis: The Endothelial Cell as a Checkpoint for Immunological Patrolling. Cancers (2020) 12:3380. doi: 10.3390/cancers 12113380

19. Strohmeyer D, Rössing C, Bauerfeind A, Kaufmann O, Schlechte H, Bartsch G, et al. Vascular Endothelial Growth Factor and Its Correlation With Angiogenesis and P53 Expression in Prostate Cancer. Prostate (2000) 45:21624. doi: 10.1002/1097-0045(20001101)45:3<216::aid-pros3>3.0.co;2-c

20. Duque JLF, Loughlin KR, Adam RM, Kantoff PW, Zurakowski D, Freeman MR. Plasma Levels of Vascular Endothelial Growth Factor Are Increased in Patients With Metastatic Prostate Cancer. Urology (1999) 54:523-7. doi: 10.1016/S0090-4295(99)00167-3

21. Doll JA, Reiher FK, Crawford SE, Pins MR, Campbell SC, Bouck NP. Thrombospondin-1, Vascular Endothelial Growth Factor and Fibroblast Growth Factor-2 Are Key Functional Regulators of Angiogenesis in the Prostate. Prostate (2001) 49:293-305. doi: 10.1002/pros.10025
22. Borre M, Nerstrøm B, Overgaard J. Association Between Immunohistochemical Expression of Vascular Endothelial Growth Factor (VEGF), VEGF-Expressing Neuroendocrine-Differentiated Tumor Cells, and Outcome in Prostate Cancer Patients Subjected to Watchful Waiting. Clin Cancer Res (2000) 6:1882-90.

23. Bok RA, Halabi S, Fei DT, Rodriquez CR, Hayes DF, Vogelzang NJ, et al. Vascular Endothelial Growth Factor and Basic Fibroblast Growth Factor Urine Levels as Predictors of Outcome in Hormone-Refractory Prostate Cancer Patients: A Cancer and Leukemia Group B Study. Cancer Res (2001) 61:2533-6

24. Shariat SF, Anwuri VA, Lamb DJ, Shah NV, Wheeler TM, Slawin KM. Association of Preoperative Plasma Levels of Vascular Endothelial Growth Factor and Soluble Vascular Cell Adhesion Molecule-1 With Lymph Node Status and Biochemical Progression After Radical Prostatectomy. JCO (2004) 22:1655-63. doi: 10.1200/JCO.2004.09.142

25. Mukherji D, Temraz S, Wehbe D, Shamseddine A. Angiogenesis and AntiAngiogenic Therapy in Prostate Cancer. Crit Rev Oncol/Hematol (2013) 87:122-31. doi: 10.1016/j.critrevonc.2013.01.002

26. Ribatti D, Solimando AG, Pezzella F. The Anti-VEGF(R) Drug Discovery Legacy: Improving Attrition Rates by Breaking the Vicious Cycle of Angiogenesis in Cancer. Cancers (2021) 13:3433. doi: 10.3390/cancers13143433

27. Solimando AG, Da Vià MC, Leone P, Borrelli P, Croci GA, Tabares $\mathrm{P}$, et al. Halting the Vicious Cycle Within the Multiple Myeloma Ecosystem: Blocking JAM-A on Bone Marrow Endothelial Cells Restores Angiogenic Homeostasis and Suppresses Tumor Progression. Haematol (2020) 106:1943-56. doi: 10.3324/haematol.2019.239913

28. Rao L, Giannico D, Leone P, Solimando AG, Maiorano E, Caporusso C, et al. HB-EGF-EGFR Signaling in Bone Marrow Endothelial Cells Mediates Angiogenesis Associated With Multiple Myeloma. Cancers (2020) 12:173. doi: $10.3390 /$ cancers 12010173

29. Solimando AG, Annese T, Tamma R, Ingravallo G, Maiorano E, Vacca A, et al. New Insights Into Diffuse Large B-Cell Lymphoma Pathobiology. Cancers (2020) 12:1869. doi: 10.3390/cancers12071869

30. Krebs M, Solimando AG, Kalogirou C, Marquardt A, Frank T, Sokolakis I, et al. MiR-221-3p Regulates VEGFR2 Expression in High-Risk Prostate Cancer and Represents an Escape Mechanism From Sunitinib In Vitro. JCM (2020) 9:670. doi: 10.3390/jcm9030670

31. Melegh Z, Oltean S. Targeting Angiogenesis in Prostate Cancer. IJMS (2019) 20:2676. doi: 10.3390/ijms20112676

32. Sarkar C, Goswami S, Basu S, Chakroborty D. Angiogenesis Inhibition in Prostate Cancer: An Update. Cancers (2020) 12:2382. doi: 10.3390/ cancers 12092382

33. Kelly WK, Halabi S, Carducci M, George D, Mahoney JF, Stadler WM, et al. Randomized, Double-Blind, Placebo-Controlled Phase III Trial Comparing Docetaxel and Prednisone With or Without Bevacizumab in Men With Metastatic Castration-Resistant Prostate Cancer: CALGB 90401. JCO (2012) 30:1534-40. doi: 10.1200/JCO.2011.39.4767

34. Tannock IF, Fizazi K, Ivanov S, Karlsson CT, Fléchon A, Skoneczna I, et al. Aflibercept Versus Placebo in Combination With Docetaxel and Prednisone for Treatment of Men With Metastatic Castration-Resistant Prostate Cancer (VENICE): A Phase 3, Double-Blind Randomised Trial. Lancet Oncol (2013) 14:760-8. doi: 10.1016/S1470-2045(13)70184-0

35. Michaelson MD, Oudard S, Ou Y-C, Sengeløv L, Saad F, Houede N, et al. Randomized, Placebo-Controlled, Phase III Trial of Sunitinib Plus Prednisone Versus Prednisone Alone in Progressive, Metastatic, Castration-Resistant Prostate Cancer. JCO (2014) 32:76-82. doi: 10.1200/ JCO.2012.48.5268

36. Petrylak DP, Vogelzang NJ, Budnik N, Wiechno PJ, Sternberg CN, Doner K, et al. Docetaxel and Prednisone With or Without Lenalidomide in Chemotherapy-Naive Patients With Metastatic Castration-Resistant Prostate Cancer (MAINSAIL): A Randomised, Double-Blind, PlaceboControlled Phase 3 Trial. Lancet Oncol (2015) 16:417-25. doi: 10.1016/ S1470-2045(15)70025-2

37. Solimando AG, Vacca A, Ribatti DA. Comprehensive Biological and Clinical Perspective Can Drive a Patient-Tailored Approach to Multiple Myeloma: Bridging the Gaps Between the Plasma Cell and the Neoplastic Niche. J Oncol (2020) 2020:1-16. doi: 10.1155/2020/6820241

38. Lamanuzzi A, Saltarella I, Desantis V, Frassanito MA, Leone P, Racanelli V, et al. Inhibition of MTOR Complex 2 Restrains Tumor Angiogenesis in 
Multiple Myeloma. Oncotarget (2018) 9:20563-77. doi: 10.18632/ oncotarget. 25003

39. Solimando AG, Da Vià MC, Cicco S, Leone P, Di Lernia G, Giannico D, et al. High-Risk Multiple Myeloma: Integrated Clinical and Omics Approach Dissects the Neoplastic Clone and the Tumor Microenvironment. JCM (2019) 8:997. doi: $10.3390 / \mathrm{jcm} 8070997$

40. Stahl M, Zeidan AM. Lenalidomide Use in Myelodysplastic Syndromes: Insights Into the Biologic Mechanisms and Clinical Applications: Use of Lenalidomide in MDS: Biology and Efficacy. Cancer (2017) 123:1703-13. doi: $10.1002 /$ cncr. 30585

41. Moschetta M, Basile A, Ferrucci A, Frassanito MA, Rao L, Ria R, et al. Novel Targeting of Phospho-CMET Overcomes Drug Resistance and Induces Antitumor Activity in Multiple Myeloma. Clin Cancer Res (2013) 19:4371-82. doi: 10.1158/1078-0432.CCR-13-0039

42. Ferrucci A, Moschetta M, Frassanito MA, Berardi S, Catacchio I, Ria R, et al. A HGF/CMET Autocrine Loop Is Operative in Multiple Myeloma Bone Marrow Endothelial Cells and May Represent a Novel Therapeutic Target. Clin Cancer Res (2014) 20:5796-807. doi: 10.1158/1078-0432.CCR-14-0847

43. Gnoni A, Licchetta A, Memeo R, Argentiero A, Solimando AG, Longo V, et al. Role of BRAF in Hepatocellular Carcinoma: A Rationale for Future Targeted Cancer Therapies. Medicina (2019) 55:754. doi: 10.3390/ medicina55120754

44. Argentiero A, Solimando AG, Krebs M, Leone P, Susca N, Brunetti O, et al. Anti-Angiogenesis and Immunotherapy: Novel Paradigms to Envision Tailored Approaches in Renal Cell-Carcinoma. JCM (2020) 9:1594. doi: $10.3390 / \mathrm{jcm} 9051594$

45. Solimando AG, Susca N, Argentiero A, Brunetti O, Leone P, De Re V, et al. Second-Line Treatments for Advanced Hepatocellular Carcinoma: A Systematic Review and Bayesian Network Meta-Analysis. Clin Exp Med (2021) 1-10. doi: 10.1007/s10238-021-00727-7

46. Gherardi E, Birchmeier W, Birchmeier C, Woude GV. Targeting MET in Cancer: Rationale and Progress. Nat Rev Cancer (2012) 12:89-103. doi: $10.1038 / \mathrm{nrc} 3205$

47. Chatterjee S, Heukamp LC, Siobal M, Schöttle J, Wieczorek C, Peifer M, et al. Tumor VEGF : VEGFR2 Autocrine Feed-Forward Loop Triggers Angiogenesis in Lung Cancer. J Clin Invest (2013) 123:1732-40. doi: $10.1172 / \mathrm{JCI} 65385$

48. Smith DC, Smith MR, Sweeney C, Elfiky AA, Logothetis C, Corn PG, et al. Cabozantinib in Patients With Advanced Prostate Cancer: Results of a Phase II Randomized Discontinuation Trial. JCO (2013) 31:412-9. doi: 10.1200/ JCO.2012.45.0494

49. Schimmoller F, Zayzafoon M, Chung LWK, Zhau HE, Fagerlund KM, Aftab DT. Abstract A233: Cabozantinib (XL184), a Dual MET-VEGFR2 Inhibitor, Blocks Osteoblastic and Osteolytic Progression of Human Prostate Cancer Xenografts in Mouse Bone. In: Proceedings of the Therapeutic Agents: Small Molecule Kinase Inhibitors. San Francisco, CA: American Association for Cancer Research (2011). p. A233-3.

50. Yakes FM, Chen J, Tan J, Yamaguchi K, Shi Y, Yu P, et al. Cabozantinib (XL184), a Novel MET and VEGFR2 Inhibitor, Simultaneously Suppresses Metastasis, Angiogenesis, and Tumor Growth. Mol Cancer Ther (2011) 10:2298-308. doi: 10.1158/1535-7163.MCT-11-0264

51. Sennino B, Ishiguro-Oonuma T, Wei Y, Naylor RM, Williamson CW, Bhagwandin V, et al. Suppression of Tumor Invasion and Metastasis by Concurrent Inhibition of C-Met and VEGF Signaling in Pancreatic Neuroendocrine Tumors. Cancer Discov (2012) 2:270-87. doi: 10.1158/ 2159-8290.CD-11-0240

52. Nguyen HM, Ruppender N, Zhang X, Brown LG, Gross TS, Morrissey C, et al. Cabozantinib Inhibits Growth of Androgen-Sensitive and CastrationResistant Prostate Cancer and Affects Bone Remodeling. PloS One (2013) 8: e78881. doi: 10.1371/journal.pone.0078881

53. Dai J, Zhang H, Karatsinides A, Keller JM, Kozloff KM, Aftab DT, et al. Cabozantinib Inhibits Prostate Cancer Growth and Prevents TumorInduced Bone Lesions. Clin Cancer Res (2014) 20:617-30. doi: 10.1158/ 1078-0432.CCR-13-0839

54. Graham TJ, Box G, Tunariu N, Crespo M, Spinks TJ, Miranda S, et al. Preclinical Evaluation of Imaging Biomarkers for Prostate Cancer Bone Metastasis and Response to Cabozantinib. JNCI: J Natl Cancer Institute (2014) 106(4):dju033. doi: 10.1093/jnci/dju033
55. Stern PH, Alvares K. Antitumor Agent Cabozantinib Decreases RANKL Expression in Osteoblastic Cells and Inhibits Osteoclastogenesis and PTHrP-Stimulated Bone Resorption: Cabozantinib and the Bone Microenvironment. J Cell Biochem (2014) 2033-8. doi: 10.1002/jcb.24879. $\mathrm{n} / \mathrm{a}-\mathrm{n} / \mathrm{a}$.

56. Zhang S, Zhau HE, Osunkoya AO, Iqbal S, Yang X, Fan S, et al. Vascular Endothelial Growth Factor Regulates Myeloid Cell Leukemia-1 Expression Through Neuropilin-1-Dependent Activation of C-MET Signaling in Human Prostate Cancer Cells. Mol Cancer (2010) 9:9. doi: 10.1186/14764598-9-9

57. Smith MR, Sweeney CJ, Corn PG, Rathkopf DE, Smith DC, Hussain M, et al. Cabozantinib in Chemotherapy-Pretreated Metastatic Castration-Resistant Prostate Cancer: Results of a Phase II Nonrandomized Expansion Study. JCO (2014) 32:3391-9. doi: 10.1200/JCO.2013.54.5954

58. Basch E, Autio KA, Smith MR, Bennett AV, Weitzman AL, Scheffold C, et al. Effects of Cabozantinib on Pain and Narcotic Use in Patients With Castration-Resistant Prostate Cancer: Results From a Phase 2 Nonrandomized Expansion Cohort. Eur Urol (2015) 67:310-8. doi: 10.1016/j.eururo.2014.02.013

59. Lee RJ, Saylor PJ, Dror Michaelson M, Michael Rothenberg S, Smas ME, Miyamoto DT, et al. A Dose-Ranging Study of Cabozantinib in Men With Castration-Resistant Prostate Cancer and Bone Metastases. Clin Cancer Res (2013) 19:3088-94. doi: 10.1158/1078-0432.CCR-13-0319

60. Smith M, De Bono J, Sternberg C, Le Moulec S, Oudard S, De Giorgi U, et al. Phase III Study of Cabozantinib in Previously Treated Metastatic CastrationResistant Prostate Cancer: COMET-1. JCO (2016) 34:3005-13. doi: 10.1200/ JCO.2015.65.5597

61. Schulten H-J. Pleiotropic Effects of Metformin on Cancer. Int J Mol Sci (2018) 19(10):2850. doi: 10.3390/ijms 19102850

62. Keizman D, Ish-Shalom M, Sella A, Gottfried M, Maimon N, Peer A, et al. Metformin Use and Outcome of Sunitinib Treatment in Patients With Diabetes and Metastatic Renal Cell Carcinoma. Clin Genitourin Cancer (2016) 14:420-5. doi: 10.1016/j.clgc.2016.04.012

63. Hamieh L, McKay RR, Lin X, Moreira RB, Simantov R, Choueiri TK. Effect of Metformin Use on Survival Outcomes in Patients With Metastatic Renal Cell Carcinoma. Clin Genitourin Cancer (2017) 15:221-9. doi: 10.1016/ j.clgc.2016.06.017

64. Marquardt A, Solimando AG, Kerscher A, Bittrich M, Kalogirou C, Kübler $\mathrm{H}$, et al. Subgroup-Independent Mapping of Renal Cell CarcinomaMachine Learning Reveals Prognostic Mitochondrial Gene Signature Beyond Histopathologic Boundaries. Front Oncol (2021) 11:621278. doi: $10.3389 /$ fonc.2021.621278

65. Schöpf B, Weissensteiner H, Schäfer G, Fazzini F, Charoentong P, Naschberger A, et al. OXPHOS Remodeling in High-Grade Prostate Cancer Involves MtDNA Mutations and Increased Succinate Oxidation. Nat Commun (2020) 11:1487. doi: 10.1038/s41467-020-15237-5

66. Huss WJ, Hanrahan CF, Barrios RJ, Simons JW, Greenberg NM. Angiogenesis and Prostate Cancer: Identification of a Molecular Progression Switch. Cancer Res (2001) 61:2736-43.

67. Annese T, Tamma R, De Giorgis M, Ribatti D. MicroRNAs Biogenesis, Functions and Role in Tumor Angiogenesis. Front Oncol (2020) 10:581007. doi: $10.3389 /$ fonc. 2020.581007

68. Liu C, Kelnar K, Vlassov AV, Brown D, Wang J, Tang DG. Distinct MicroRNA Expression Profiles in Prostate Cancer Stem/Progenitor Cells and Tumor-Suppressive Functions of Let-7. Cancer Res (2012) 72:3393-404. doi: 10.1158/0008-5472.CAN-11-3864

69. Xie P, Liu M, Chen F, Wu S, Shao T, Wang W, et al. Long Non-Coding RNA AGAP2-AS1 Silencing Inhibits PDLIM5 Expression Impeding Prostate Cancer Progression via Up-Regulation of MicroRNA-195-5p. Front Genet (2020) 11:1030. doi: 10.3389/fgene.2020.01030

70. Kalogirou C, Linxweiler J, Schmucker P, Snaebjornsson MT, Schmitz W, Wach S, et al. MiR-205-Driven Downregulation of Cholesterol Biosynthesis Through SQLE-Inhibition Identifies Therapeutic Vulnerability in Aggressive Prostate Cancer. Nat Commun (2021) 12:5066. doi: 10.1038/s41467-02125325-9

71. Moschetta M, Mishima Y, Kawano Y, Manier S, Paiva B, Palomera L, et al. Targeting Vasculogenesis to Prevent Progression in Multiple Myeloma. Leukemia (2016) 30:1103-15. doi: 10.1038/leu.2016.3 
72. Solimando AG, Da Via' MC, Leone P, Croci G, Borrelli P, Tabares Gaviria P, et al. Adhesion-Mediated Multiple Myeloma (MM) Disease Progression: Junctional Adhesion Molecule a Enhances Angiogenesis and Multiple Myeloma Dissemination and Predicts Poor Survival. Blood (2019) 134:855-5. doi: 10.1182/blood-2019-126674

73. Huinen ZR, Huijbers EJM, van Beijnum JR, Nowak-Sliwinska P, Griffioen AW. Anti-Angiogenic Agents - Overcoming Tumour Endothelial Cell Anergy and Improving Immunotherapy Outcomes. Nat Rev Clin Oncol (2021) 18:527-40. doi: 10.1038/s41571-021-00496-y

74. Chouaib S, Messai Y, Couve S, Escudier B, Hasmim M, Noman MZ. Hypoxia Promotes Tumor Growth in Linking Angiogenesis to Immune Escape. Front Immun (2012) 3:21. doi: 10.3389/fimmu.2012.00021

75. Song Y, Fu Y, Xie Q, Zhu B, Wang J, Zhang B. Anti-Angiogenic Agents in Combination With Immune Checkpoint Inhibitors: A Promising Strategy for Cancer Treatment. Front Immunol (2020) 11:1956. doi: 10.3389/fimmu.2020.01956

76. Mateo J, Carreira S, Sandhu S, Miranda S, Mossop H, Perez-Lopez R, et al. DNA-Repair Defects and Olaparib in Metastatic Prostate Cancer. N Engl J Med (2015) 373:1697-708. doi: 10.1056/NEJMoa1506859

77. Pritchard CC, Mateo J, Walsh MF, De Sarkar N, Abida W, Beltran H, et al. Inherited DNA-Repair Gene Mutations in Men With Metastatic Prostate Cancer. N Engl J Med (2016) 375:443-53. doi: 10.1056/NEJMoa1603144

78. Taylor RA, Fraser M, Livingstone J, Espiritu SMG, Thorne H, Huang V, et al. Germline BRCA2 Mutations Drive Prostate Cancers With Distinct Evolutionary Trajectories. Nat Commun (2017) 8:13671. doi: 10.1038/ ncomms 13671

79. Abida W, Campbell D, Patnaik A, Sautois B, Shapiro J, Vogelzang NJ, et al. Preliminary Results From the TRITON2 Study of Rucaparib in Patients (Pts) With DNA Damage Repair (DDR)-Deficient Metastatic CastrationResistant Prostate Cancer (MCRPC): Updated Analyses. Ann Oncol (2019) 30:v327-8. doi: 10.1093/annonc/mdz248.003

80. Smith MR, Sandhu SK, Kelly WK, Scher HI, Efstathiou E, Lara PN, et al. PreSpecified Interim Analysis of GALAHAD: A Phase II Study of Niraparib in Patients (Pts) With Metastatic Castration-Resistant Prostate Cancer (MCRPC) and Biallelic DNA-Repair Gene Defects (DRD). Ann Oncol (2019) 30:v884-5. doi: 10.1093/annonc/mdz394.043

81. Kwon J, Bakhoum SF. The Cytosolic DNA-Sensing CGAS-STING Pathway in Cancer. Cancer Discovery (2020) 10:26-39. doi: 10.1158/2159-8290.CD-19-0761

82. Hoong BYD, Gan YH, Liu H, Chen ES. CGAS-STING Pathway in Oncogenesis and Cancer Therapeutics. Oncotarget (2020) 11:2930-55. doi: $10.18632 /$ oncotarget.27673

83. Teply BA, Antonarakis ES. Treatment Strategies for DNA Repair-Deficient Prostate Cancer. Expert Rev Clin Pharmacol (2017) 10:889-98. doi: 10.1080/ 17512433.2017.1338138

84. Melo CM, Vidotto T, Chaves LP, Lautert-Dutra W, Reis RBD, Squire JA. The Role of Somatic Mutations on the Immune Response of the Tumor Microenvironment in Prostate Cancer. Int J Mol Sci (2021) 22:9550. doi: 10.3390/ijms22179550

85. Arranz Arija JA, Yu EY, Piulats JM, Gravis G, Laguerre B, Oudard S, et al. 621p Pembrolizumab (Pembro) Plus Olaparib in Patients (Pts) With Docetaxel-Pretreated Metastatic Castration-Resistant Prostate Cancer (MCRPC): KEYNOTE-365 Cohort A Update. Ann Oncol (2020) 31:S5134. doi: 10.1016/j.annonc.2020.08.880

86. Yu E, Xu L, Kim J, Antonarakis ES. KEYLYNK-010: Phase III Study of Pembrolizumab (Pembro) Plus Olaparib (OLA) vs Enzalutamide (ENZA) or Abiraterone (ABI) in ENZA- or ABI-Pretreated Patients (Pts) With Metastatic Castration-Resistant Prostate Cancer (MCRPC) Who Had Progression on Chemotherapy (CTx). Ann Oncol (2019) 30:v351-2. doi: 10.1093/annonc/ mdz248.050

87. Nizialek E, Antonarakis ES. PARP Inhibitors in Metastatic Prostate Cancer: Evidence to Date. Cancer Manag Res (2020) 12:8105-14. doi: 10.2147/ CMAR.S227033

88. Antonarakis ES, Gomella LG, Petrylak DP. When and How to Use PARP Inhibitors in Prostate Cancer: A Systematic Review of the Literature With an Update on On-Going Trials. Eur Urol Oncol (2020) 3:594-611. doi: 10.1016/ j.euo.2020.07.005

89. Hussain M, Mateo J, Fizazi K, Saad F, Shore N, Sandhu S, et al. Survival With Olaparib in Metastatic Castration-Resistant Prostate Cancer. N Engl J Med (2020) 383:2345-57. doi: 10.1056/NEJMoa2022485
90. Castro E, Romero-Laorden N, Del Pozo A, Lozano R, Medina A, Puente J, et al. PROREPAIR-B: A Prospective Cohort Study of the Impact of Germline DNA Repair Mutations on the Outcomes of Patients With Metastatic Castration-Resistant Prostate Cancer. J Clin Oncol (2019) 37:490-503. doi: $10.1200 / J C O .18 .00358$

91. Eisermann K, Fraizer G. The Androgen Receptor and VEGF: Mechanisms of Androgen-Regulated Angiogenesis in Prostate Cancer. Cancers (2017) 9:32. doi: $10.3390 /$ cancers 9040032

92. Tentori L, Lacal PM, Muzi A, Dorio AS, Leonetti C, Scarsella M, et al. Poly(ADPRibose) Polymerase (PARP) Inhibition or PARP-1 Gene Deletion Reduces Angiogenesis. Eur J Cancer (2007) 43:2124-33. doi: 10.1016/j.ejca.2007.07.010

93. Rajesh M, Mukhopadhyay P, Godlewski G, Bátkai S, Haskó G, Liaudet L, et al. Poly(ADP-Ribose)Polymerase Inhibition Decreases Angiogenesis. Biochem Biophys Res Commun (2006) 350:1056-62. doi: 10.1016/j.bbrc.2006.09.160

94. Touat M, Ileana E, Postel-Vinay S, André F, Soria J-C. Targeting FGFR Signaling in Cancer. Clin Cancer Res (2015) 21:2684-94. doi: 10.1158/10780432.CCR-14-2329

95. Giacomini A, Grillo E, Rezzola S, Ribatti D, Rusnati M, Ronca R, et al. The FGF/FGFR System in the Physiopathology of the Prostate Gland. Physiol Rev (2021) 101:569-610. doi: 10.1152/physrev.00005.2020

96. Hanahan D, Bergers G, Bergsland E. Less Is More, Regularly: Metronomic Dosing of Cytotoxic Drugs Can Target Tumor Angiogenesis in Mice. J Clin Invest (2000) 105:1045-7. doi: 10.1172/JCI9872

97. Kerbel RS, Kamen BA. The Anti-Angiogenic Basis of Metronomic Chemotherapy. Nat Rev Cancer (2004) 4:423-36. doi: 10.1038/nrc1369

98. Derosa L, Galli L, Orlandi P, Fioravanti A, Di Desidero T, Fontana A, et al. Docetaxel Plus Oral Metronomic Cyclophosphamide: A Phase II Study With Pharmacodynamic and Pharmacogenetic Analyses in Castration-Resistant Prostate Cancer Patients: Docetaxel and Metronomic Chemotherapy. Cancer (2014) 120:3923-31. doi: 10.1002/cncr.28953

99. Barroso-Sousa R, da Fonseca LG, Souza KT, Chaves ACR, Kann AG, de Castro G, et al. Metronomic Oral Cyclophosphamide Plus Prednisone in Docetaxel-Pretreated Patients With Metastatic Castration-Resistant Prostate Cancer. Med Oncol (2015) 32:443. doi: 10.1007/s12032-014-0443-4

100. Calvani N, Morelli F, Naglieri E, Gnoni A, Chiuri VE, Orlando L, et al. Metronomic Chemotherapy With Cyclophosphamide Plus Low Dose of Corticosteroids in Advanced Castration-Resistant Prostate Cancer Across the Era of Taxanes and New Hormonal Drugs. Med Oncol (2019) 36:80. doi: 10.1007/s12032-019-1304-y

101. Caffo O, Facchini G, Biasco E, Ferraù F, Morelli F, Donini M, et al. Activity and Safety of Metronomic Cyclophosphamide in the Modern Era of Metastatic Castration-Resistant Prostate Cancer. Future Oncol (2019) 15:1115-23. doi: 10.2217/fon-2018-0715

102. Ladoire S, Eymard JC, Zanetta S, Mignot G, Martin E, Kermarrec I, et al. Metronomic Oral Cyclophosphamide Prednisolone Chemotherapy Is an Effective Treatment for Metastatic Hormone-Refractory Prostate Cancer After Docetaxel Failure. Anticancer Res (2010) 30:4317-23.

103. Di Desidero T, Derosa L, Galli L, Orlandi P, Fontana A, Fioravanti A, et al. Clinical, Pharmacodynamic and Pharmacokinetic Results of a Prospective Phase II Study on Oral Metronomic Vinorelbine and Dexamethasone in Castration-Resistant Prostate Cancer Patients. Invest N Drugs (2016) 34:76070. doi: 10.1007/s10637-016-0385-0

104. Fontana A, Galli L, Fioravanti A, Orlandi P, Galli C, Landi L, et al. Clinical and Pharmacodynamic Evaluation of Metronomic Cyclophosphamide, Celecoxib, and Dexamethasone in Advanced Hormone-Refractory Prostate Cancer. Clin Cancer Res (2009) 15:4954-62. doi: 10.1158/1078-0432.CCR08-3317

105. Laheurte C, Thiery-Vuillemin A, Calcagno F, Legros A, Simonin H, Boullerot $\mathrm{L}$, et al. Metronomic Cyclophosphamide Induces Regulatory T Cells Depletion and PSA-Specific T Cells Reactivation in Patients With Biochemical Recurrent Prostate Cancer. Int J Cancer (2020) 147:1199-205. doi: $10.1002 / \mathrm{ijc} .32803$

106. Mitra Ghosh T, White J, Davis J, Mazumder S, Kansom T, Skarupa E, et al. Identification and Characterization of Key Differentially Expressed Genes Associated With Metronomic Dosing of Topotecan in Human Prostate Cancer. Front Pharmacol (2021) 12:736951. doi: 10.3389/fphar.2021.736951

107. Chang SS, Reuter VE, Heston WD, Bander NH, Grauer LS, Gaudin PB. Five Different Anti-Prostate-Specific Membrane Antigen (PSMA) Antibodies 
Confirm PSMA Expression in Tumor-Associated Neovasculature. Cancer Res (1999) 59:3192-8.

108. Nguyen DP, Xiong PL, Liu H, Pan S, Leconet W, Navarro V, et al. Induction of PSMA and Internalization of an Anti-PSMA MAb in the Vascular Compartment. Mol Cancer Res (2016) 14:1045-53. doi: 10.1158/1541-7786.MCR-16-0193

109. Derlin T, Kreipe H-H, Schumacher U, Soudah B. PSMA Expression in Tumor Neovasculature Endothelial Cells of Follicular Thyroid Adenoma as Identified by Molecular Imaging Using 68ga-PSMA Ligand PET/CT. Clin Nucl Med (2017) 42:e173-4. doi: 10.1097/RLU.0000000000001487

Conflict of Interest: The authors declare that the research was conducted in the absence of any commercial or financial relationships that could be construed as a potential conflict of interest.
Publisher's Note: All claims expressed in this article are solely those of the authors and do not necessarily represent those of their affiliated organizations, or those of the publisher, the editors and the reviewers. Any product that may be evaluated in this article, or claim that may be made by its manufacturer, is not guaranteed or endorsed by the publisher.

Copyright $\odot 2022$ Solimando, Kalogirou and Krebs. This is an open-access article distributed under the terms of the Creative Commons Attribution License (CC BY). The use, distribution or reproduction in other forums is permitted, provided the original author(s) and the copyright owner(s) are credited and that the original publication in this journal is cited, in accordance with accepted academic practice. No use, distribution or reproduction is permitted which does not comply with these terms. 